\title{
INOVASI PENDIDIKAN ERA REVOLUSI INDUSTRI 4.0
}

\author{
ZHAHRATUL HAFIZHAH \\ Email: $1810111320007 @$ mhs.ulm.ac.id \\ Program Studi Pendidikan Sejarah Fakultas Keguruan dan Ilmu Pendidikan \\ Universitas Lambung Mangkurat \\ Banjarmasin
}

\begin{abstract}
Abstrak
Inovasi pendidikan adalah suatu perubahan yang baru, dan kualitatif berbeda dari hal (yang ada sebelumnya), serta sengaja diusahakan untuk meningkatkan kemampuan guna mencapai tujuan tertentu dalam pendidikan. Tegasnya inovasi pendidikan adalah inovasi (pembaruan) dalam bidang pendidikan atau inovasi yang dilakukan untuk memecahkan masalah-masalah pendidikan, inovasi pendidikan merupakan suatu ide, barang, metode yang dirasakan atau diamati sebagai hal baru bagi seseorang atau kelompok orang (masyarakat) baik berupa hasil invensi (yang baru) atau discovery (mengubah yg lama) yang digunakan untuk mencapai tujuan pendidikan atau memecahkan masalah-masalah pendidikan. Peran guru dalam inovasi dan pengembangan media pembelajaran sangat diperlukan mengingat guru dapat dikatakan sebagai pemain yang sangat berperan dalam proses belajar mengajar di kelas, hendaknya dapat mengolah kemampuannya untuk membuat media pembelajaran yang efektif dan efisien. Tantangan pendidikan di era industri 4 , dapat diperinci sebagai berikut. 1) Memberikan pemahaman atau pengetahuan kepada seluruh pendidik untuk mampu memanfaatkan ICT dalam pembelajaran, membimbing siswa dalam menggunakan ICT dan mempermudah pelaksanaan pendidikan di seluruh wilayah Indonesia.
\end{abstract}

\section{PENDAHULUAN}

Menurut Syafaruddin, Asrul, dan Mesiono, (2012: 22-23) dalam buku Inovasi Pendidikan (Suatu Analisis Terhadap Kebijakan Baru Pendidikan), istilah "inovasi” merupakan kata yang menarik dalam manajemen pada tiga dasawarsa belakangan. Para 
pimpinan bisnis dan politisi dalam memenangkan persaingan selalu menggunakan istilah inovasi atau perubahan radikal sebagai jargon kompetisi dan perjuang bisnis dalam kiprahnya. Istilah inovasi, perubahan dan pembaharuan seringkali dipakai secara silih berganti untuk menjelaskan tentang inovasi. Berdasarkan studi Center for Educational research and Innovation tahun 1973 sudah didefinisikan bahwa menunjukkan sesuatu tindakan yang baru dalam organisasi dan kehidupan manusia. Dalam hal ini inovasi sebagai suatu usaha yang dilakukan secara sengaja untuk meningkatkan praktik dalam mencapai tujuan dan selanjutnya dinyatakan suatu pembaharuan adalah suatu inovasi dari suatu sistem dalam skala yang luas (Junius Mauegha, 1982: 89). Secara singkat inovasi dimaksudkan sebagai "pembaharuan", baik berupa idea atau gagasan, kelakuan atau benda, sebagaimana dinyatakan bahwa: "An innovation is here defined as any thought, behavior, or thing that is new because it is qualitatively different from existing forces" demikian pendapat Barnett, (1953:7) sebagaimana dikutip oleh Asy'ari (tt:70). Para pakar pendidikan telah banyak mengajukan definisi inovasi pendidikan. Namun disini dipaparkan beberapa pendapat tentang desfinisi inovasi pendidikan sebagai upaya dalam memahami konsep dasar inovasi pendidikan yang dipraktikkan dalam dunia pendidikan. Pada dasarnya inovasi pendidikan merupakan upaya dalam memperbaiki aspek-aspek pendidikan dalam praktiknya. Untuk lebih jelasnya Inovasi pendidikan Inovasi pendidikan adalah suatu perubahan yang baru, dan kualitatif berbeda dari hal (yang ada sebelumnya), serta sengaja diusahakan untuk meningkatkan kemampuan guna mencapai tujuan tertentu dalam pendidikan (Sa'ud: 2011, 5). Dalam konteks ini dapat dipahami bahwa inovasi pendidikan adalah suatu perubahan yang baru dan kualitatif berbeda dari keadaan yang ada sebelumnya dengan sengaja diusahakan untuk meningkatkan kemampuan guna mencapai tujuan tertentu secara maksimal dalam pendidikan. Tegasnya inovasi pendidikan adalah inovasi (pembaruan) dalam bidang pendidikan atau inovasi yang dilakukan untuk memecahkan masalah-masalah pendidikan, inovasi pendidikan merupakan suatu ide, barang, metode yang dirasakan atau diamati sebagai hal baru bagi seseorang atau kelompok orang (masyarakat) baik berupa hasil invensi (yang baru) atau discovery (mengubah yg lama) yang digunakan untuk mencapai tujuan pendidikan atau memecahkan masalah-masalah pendidikan. (Syafaruddin, Asrul, dan Mesiono, 2012: 52) 


\section{PERAN GURU SEBAGAI SEBUAH PROFESI}

Peran guru dalam inovasi dan pengembangan media pembelajaran sangat diperlukan mengingat guru dapat dikatakan sebagai pemain yang sangat berperan dalam proses belajar mengajar di kelas, hendaknya dapat mengolah kemampuannya untuk membuat media pembelajaran yang efektif dan efisien. Hal ini, menurut Wijaya dkk (1991:2), disebabkan perkembangan jaman yang terus terjadi tanpa henti dengan kurun waktu tertentu. Lembaga pendidikan hendaknya tidak hanya puas dengan metode dan teknik lama, yang menekankan pada metode hafalan, sehingga tidak atau kurang ada maknanya jika diterapkan pada masa sekarang. Perkembangan jaman yang begitu pesat dewasa ini membuat siswa semakin akrab dengan berbagai hal yang baru, seiring dengan perkembangan dunia informasi dan Komunikasi. Karena itu, sangat wajar jika kondisi ini harus diperhatikan oleh guru agar terus mengadakan pembaharuan (inovasi), (Yunani, 2009: 6).

Untuk dapat merencanakan proses pembelajaran secara inovatif yang mampu memberikan pengalaman yang berguna bagi siswa kita perlu memperhatikan komponen penting proses pembelajaran. Dari komponen proses pembelajaran itu guru dapat merencanakan kegiatan dan strategi pembelajaran yang relevan dengan tujuan belajar. Strategi pengembangan pembelajaran ini menjadi penting karena adanya beberapa persoalan dalam proses belajar yang mungkin ada dalam sebuah system pembelajaran. Strategi pengembangan pembelajaran meliputi:

a. Persiapan, mencakup Analisis Kurikulum, analisis kebutuhan maupun desain pembelajaran.

b. Metode yang digunakan secara umum adalah, klasikal, kelompok, individual.

c. Evaluasi diperluakan untuk mengetahui apakah strategi yang digunakan cocok atau tidak.

Persoalannya sekarang ialah, bagaiamana fungsi 3 komponen (Guru, Siswa, dan Kurikulum/materi) dapat saling memberikan dukungan secara sinergis terhadap proses pembelajaran sehingga mampu melahirkan pengalaman beharga bagi kehidupan siswa dimasa yang akan dating manakala siswa itu mengarungi kehidupan nyata dalam 
masyarakat. Dari segi guru, misalnya , perlu memiliki visi dan misi yang jelas terhadap masa depan siswa. Ini berarti bahwa guru perlu memiliki wawasan yang berorinetasi pada masa depan. Dengan demikian guru harus selalu memberikan informasi yang mutakhir dalam bidang yang diajarkannya. Juga perlu memiliki kemampuan untuk memprediksi mengenai apa yang akan muncul dan apa yang akan tenggelam dari aplikasi bidang studi yang akan diajarkannya. (Yunani, 2009: 6-7)

Sebagai dasar untuk memanfaatkan internet sebagai media pembelajaran dalam seting sekolah, ada beberapa hal yang perlu mendapat perhatian dan penanganan yang sehus agar penyelenggaraan pemanfaatan internet untuk pembelajaran bisa berhasil yaitu:

1. Faktor Lingkungan, yang meliputi institusi penyelenggara pendidikan dan masyarakat.

2. Siswa atau peserta didik meliputi usia, latarbelakang, budaya, penguasaan bahasa dan berbagai gaya belajarnya.

3. Guru atau pendidik mellputi latar belakang, usia, gaya mengajar, pengalaman dan personalitinya.

4. Faktor teknologi meliputi komputer, perangkat lunak, jaringan, koneksi ke internet dan berbagal kemampuan yang dibutuhkan berkaitan dengan penerapan internet di lingkungan sekolah. (Sa’ud, 2017: 190)

Peranan guru tak kalah menentukannya terhadap keberhasilan pemanfaatan internet di sekolah. Pemantauan sementara dibeberapa sekolah dasar, dan menengah di Bandung umumnya menunjukkan bahwa inisiatif pemanfaatan internet di sekolah justru banyak yang datang dari guru-guru yang memiliki kesadaran lebih awal tentang potensi internet guna menunjang proses belajar mengajar. Keberhasilan pernbelajaran berbasis internet ini secara signifikan ditentukan oleh karakteristik guru-guru yang akan dilibatkan dalam pemanfaatan internet. Untuk itu perlu diperhatikan hal-hal sebagai berikut.

1. Guru perlu diberikan pemahaman berbagai keuntungan, termasuk kelebihan dan kelemahan penggunaan internet untuk pembelajaran, sehingga mereka memiliki motivasi dan komitmen yang cukup tinggi.

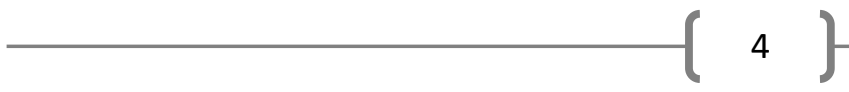


2. Guru, baik nantinya dia akan berperan sebagai pengembang dan pengguna maupun yang diproyeksikan sebagal pengelola sistem pembelajaran berbasis internet, harus dibekali dengan kesadaran, wawasan, pengetahuan dan keterampilan tentang internet.

3. Guru yang akan dilibatkan dalarn pengembangan dan pemanfaatan internet untuk pembelajaran hendaknya memiliki pengalaman dan kermampuan mengajar yang cukup.

4. Jumlah guru yang akan dilibatkan dalam pengembangan dan pemanfaatan internet untuk pembelajaran, hendaknya disesuaikan dengan kebutuhan dan dilakukan secara bertahap.

5. Guru harus memiliki komitmen dan keseriusan dalam menangani pengembangan dan pemanfaatan internet untuk pembelajaran.

6. Tetap menjaga gaya mengajar tiap-tiap guru. karena hal itu akan dicerminkan dalam cara pembelajaran mereka kelalk di sistem pembelajaran dengan internet. (Sa'ud, 2017: 192-193).

\section{GURU INDONESIA DAN TANTANGAN PROFESIONALISME}

Penggunaan teknologi informasi dalam inovasi pendidikan di era kekinian menurut Menristekdikti (2018) bahwa dalam menghadapi era revolusi industri 4 beberapa hal yang harus dipersiapkan diantaranya:

A. Persiapan sistem pembelajaran yang lebih inovatif . untuk menghasilkan lulusan yang kompetitif dan terampil terutama dalam aspek data literacy, technological literacy and human literacy.

B. Rekonstruksi kebijakan kelembagaan pendidikan tinggi yang adaptif dan responsif terhadap revolusi industri 4.0 dalam mengembangkan transdisiplin ilmu dan program studi yang dibutuhkan.

C. Persiapan sumber daya manusia yang responsive, adaptif dan handal untuk menghadapi revolusi industri 4.

D. Peremajaan sarana prasarana dan pembangunan infrastruktur pendidikan, riset, dan inovasi juga perlu dilakukan untuk menopang kualitas pendidikan, riset, dan inovasi. (Syamsuar, Reflianto, 2018: 8). 
Tantangan pendidikan di era industri 4 , dapat diperinci sebagai berikut. 1) Memberikan pemahaman atau pengetahuan kepada seluruh pendidik untuk mampu memanfaatkan ICT dalam pembelajaran, membimbing siswa dalam menggunakan ICT dan mempermudah pelaksanaan pendidikan di seluruh wilayah Indonesia. 2) Memberikan pelatihan, pendampingan, dan evaluasi secara kontinyu pada pendidik untuk mewujudkan pendidik responsive, handal, dan adaptif 3) Menyiapkan pendidik untuk dapat menciptakan pembelajaran yang inovatif, sehingga dapat memberikan kesempatan pada anak untuk untuk kreatif, memecahkan masalah, mengoptimalkan kemampuan literasi dan numeracy, kolaborasi, dan berpikir kritis. 4) Memberikan pendidikan kewarganegaraan yang bermakna bagi siswa, sebagai bagian dari pendidikan nilai untuk mewujudkan manusia yang berkarakter. (Syamsuar, Reflianto, 2018: 11).

Di era globalisasi dan informasi ini penggunaan media pembelajaran berbasis Teknologi Informasi (TI) menjadi sebuah kebutuhan dan tuntutan namun dalam implementasinya bukanlah merupakan hal yang mudah. Dalam menggunakan media tersebut harus memperhatikan beberapa teknik agar media yang dipergunakan itu dapat dimanfaatkan dengan maksimal dan tidak menyimpang dari tujuan media tersebut. (Muhson, 2010: 7). Teknologi jaringan komputer/internet memberi manfaat bagi pemakainya untuk melakukan komunikasi secara langsung dengan pemakai lainnya. Hal ini dimungkinkan dengan diciptakannya sebuah alat bernama modem. Jaringan komputer/internet memberi kemungkinan bagi pesertanya untuk melakukan komunikasi tertulis dan saling bertukar pikiran tentang kegiatan belajar yang mereka lakukan. Jaringan komputer dapat dirancang sedemikian rupa agar dosen dapat berkomunikasi dengan mahasiswa dan mahasiswa dapat melakukan interaksi belajar dengan mahasiswa yang lain. Interaksi pembelajaran dengan menggunakan jaringan komputer tidak saja dapat dilakukan secara individual, tetapi juga untuk menunjang kegiatan belajar kelompok. Pemanfaatan jaringan komputer dalam sistem pendidikan jarak jauh dikenal juga dengan istilah Computer Conferencing System (CCF). Biasanya sistem ini dilakukan melalui surat elektronik atau E-mail. Beberapa kelebihan pemanfaatan jaringan komputer dalam sistem pendidikan jarak jauh yaitu: dapat memperkaya model- 
model tutorial, dapat memecahkan masalah belajar yang dihadapi mahasiswa dalam waktu yang lebih singkat dan dapat mengatasi hambatan ruang dan waktu dalam memperoleh informasi. CCF memberi kemungkinan bagi mahasiswa dan dosen untuk melakukan interaksi pembelajaran langsung antar individu, individu dengan kelompok, dan kelompok dengan kelompok (Mason, 1994 dalam Benny A. Pribadi dan Tita Rosita, 2002:13-14).

I Ketut Gede Darma Putra (2009) mengemukakan beberapa media yang dapat digunakan dalam pembelajaran berbasis TI, adalah :

1. Internet adalah media sesungguhnya dalam pendidikan berbasis TI, karena perkembangan internet kemudian muncul model-model e-learning, distance learning, web base learning, dan istilah pendidikan berbasis TI lainnya. Internet merupakan jaringan komputer global yang mempermudah, mempercepat akses dan distribusi informasi dan pengetahuan (materi pembelajaran) sehingga materi dalam proses belajar mengajar selalu dapat diperbaharui. Sudah seharusnya dalam penerapan pendidikan berbasis TI tersedia akses internet. Saat ini wilayah Indonesia yang terjangkau jaringan internet semakin meluas hal ini sebagai dampak dari perkembangan yang pesat dari jaringan telekomunikasi. Mulai dari jaringan telepon rumah/kantor, jaringan Speedy telkom, leased line ISP, sampai dengan komunikasi melalui GPRS, 3G, HSDPA dengan memanfaatkan modem GSM dan CDMA dari provider seluler adalah sederetan teknologi yang dapat digunakan untuk akses internet. Dengan kata lain, saat ini tersedia banyak pilihan teknologi untuk melakukan koneksi pada jaringan global.

\section{SIMPULAN}

Inovasi pendidikan adalah inovasi (pembaruan) dalam bidang pendidikan atau inovasi yang dilakukan untuk memecahkan masalah-masalah pendidikan, inovasi pendidikan merupakan suatu ide, barang, metode yang dirasakan atau diamati sebagai hal baru bagi seseorang atau kelompok orang (masyarakat) baik berupa hasil invensi (yang baru) atau discovery (mengubah yg lama) yang digunakan untuk mencapai tujuan pendidikan atau memecahkan masalah-masalah pendidikan. Peran guru dalam inovasi dan pengembangan media 
pembelajaran sangat diperlukan mengingat guru dapat dikatakan sebagai pemain yang sangat berperan dalam proses belajar mengajar di kelas, hendaknya dapat mengolah kemampuannya untuk membuat media pembelajaran yang efektif dan efisien. Di era globalisasi dan informasi ini penggunaan media pembelajaran berbasis Teknologi Informasi (TI) menjadi sebuah kebutuhan dan tuntutan namun dalam implementasinya bukanlah merupakan hal yang mudah. Interaksi pembelajaran dengan menggunakan jaringan komputer tidak saja dapat dilakukan secara individual, tetapi juga untuk menunjang kegiatan belajar kelompok. Beberapa kelebihan pemanfaatan jaringan komputer dalam sistem pendidikan jarak jauh yaitu: dapat memperkaya model- model tutorial, dapat memecahkan masalah belajar yang dihadapi mahasiswa dalam waktu yang lebih singkat dan dapat mengatasi hambatan ruang dan waktu dalam memperoleh informasi.

\section{REFERENSI}

Anis, M. Z. A., Putro, H. P. N., Susanto, H., \& Hastuti, K. P. (2020). Historical Thinking Model in Achieving Cognitive Dimension of Indonesian History Learning. PalArch's Journal of Archaeology of Egypt/Egyptology, 17(7), 7894-7906.

Anis, M. Z. A., Susanto, H., \& Mardiani, F. (2021, February). Analysis of the Effectiveness of MPBH: The Mains of Mandai as a Saving Food in Banjarmasin Community. In The 2nd International Conference on Social Sciences Education (ICSSE 2020) (pp. 89-94). Atlantis Press.

Efendi, I., Prawitasari, M., \& Susanto, H. (2021). Implementasi Penilaian Pembelajaran Pada Kurikulum 2013 Mata Pelajaran Sejarah. Prabayaksa: Journal of History Education, 1(1), 21-25.

Susanto, H. (2020). Profesi Keguruan. Banjarmasin: FKIP Universitas Lambung Mangkurat.

Susanto, H., \& Akmal, H. (2018). Efektivitas Penggunaan Aplikasi Pembelajaran Berbasis Mobile Smartphone Sebagai Media Pengenalan Sejarah Lokal Masa Revolusi Fisik Di Kalimantan Selatan Pada Siswa Sekolah Menengah Atas. HISTORIA: Jurnal Program Studi Pendidikan Sejarah, 6(2), 197-206.

Susanto, H., Irmawati, I., Akmal, H., \& Abbas, E. W. (2021). Media Film Dokumenter Masuknya Islam Ke Nusantara dan Pengaruhnya Terhadap Keterampilan Berpikir Kritis Siswa. HISTORIA: Jurnal Program Studi Pendidikan Sejarah, 9(1).

Sa’ud, Udin Syaefuddin, Inovasi Pendidikan, Bandung: Alfabeta, 2011. 
Sa’ud, Udin Syaefuddin, Inovasi Pendidikan, Bandung: Alfabeta, 2017.

Syafaruddin, S., Asrul, A., Mesiono, M., Wijaya, C., \& Usiono, U. (2016). Inovasi pendidikan: suatu analisis terhadap kebijakan baru pendidikan.

Syamsuar, S., \& Reflianto, R. (2019). Pendidikan dan tantangan pembelajaran berbasis teknologi informasi di era revolusi industri 4.0. E-Tech: Jurnal Ilmiah Teknologi Pendidikan, 6(2).

Menristekdikti. 2018. Pengembangan Iptek dan Pendidikan Tinggi di Era Revolusi Industri 4.0. (Online) https://ristekdikti.go.id/pengembangan- iptek-dan-pendidikan-tinggidi-era-revolusi-industri-4-0-2/ diakses tanggal 20 April 2021.

Muhson, A. (2010). Pengembangan media pembelajaran berbasis teknologi informasi. Jurnal Pendidikan Akuntansi Indonesia, 8(2).

I Ketut Gede Darma Putra (2009) Pendidikan Berbasis Teknologi Informasi. Makalah ini disampaikan pada Rakorda Disdikpora Bali - 10 Maret 2009.

Hasan, Y. (2009). Pentingnya Inovasi Guru dalam Proses Kegiatan Belajar dan Mengajar.

Wijaya, Cece. Dkk.1991. Upaya pembaharuan dalam pendidikan dan pengajaran.Bandung: Remaja Rosdakarya. 